\title{
French Physical Society
}

\section{Société française de Physique}

\author{
President: A. Berthelot \\ Vice President: J. Friedel \\ General Secretary: F. Netter \\ Headquarters Address: \\ 33 rue Croulebarbe, Paris 13 e
}

The French Physical Society was founded in 1874 and until the Second Woild War pratically all French physicists were members of the Society. Since then the number of members has doubled to about 2500 but the actual physics community has been growing much faster.

Membership is open to all physicists who have qualifications equivalent to the 'licence' or 'maîtrise de physique', whose application is supported by two members and whose work in education, or research, or other branch of activity, contributes to the development of physics in France. The membership fee is 80 French Francs for physicists resident in France and 90 French Francs for physicists resident in other countries. There are special reduced subscriptions to help young physicists.

The Society has its headquarters in Paris but there are regional branches throughout France - at Besançon, Bordeaux, Caen, Clermont-Ferrand, Dijon, Grenoble, Lille, Lyon, Marseille, Montpellier, Nancy, Poitiers, Rennes, Strasbourg, and Toulouse.

The Society is a completely independent forum for the discussion of major problems involving the physics community, of science education and of recent developments in the field of physics. Among its major activities are the organization of colloquia on topical subjects in physics, the organization of an exhibition in alternate years, the production of physics journals, and involvement in science education via an Education Committee.

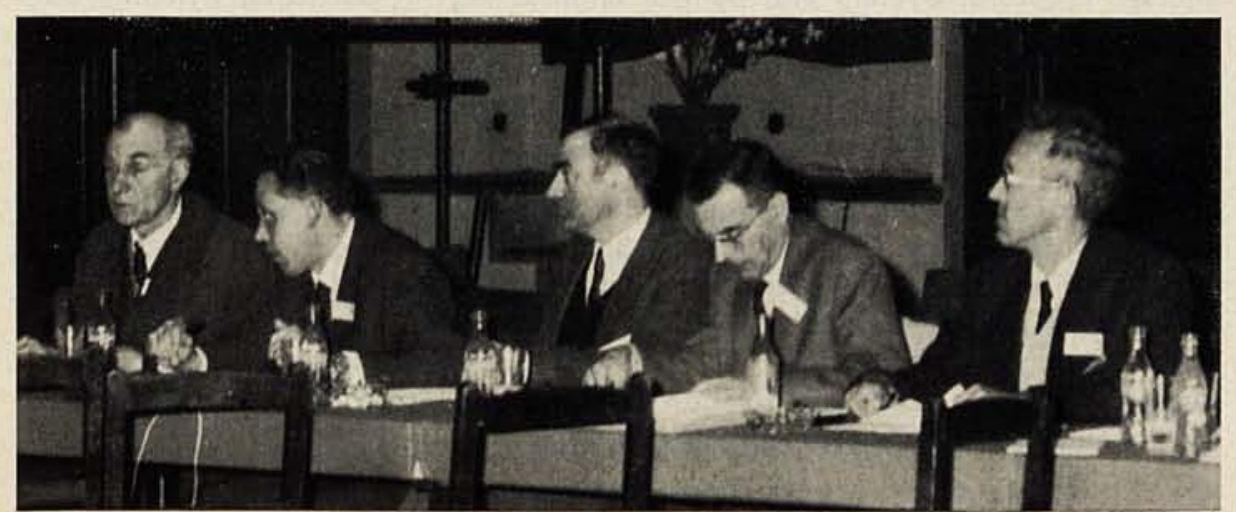

The organization of major colloquia began fifteen years ago with the help of specialist sections and they have been held with increasing frequency over the past five years at centres throughout France. The first half of the 1969 programme has included, for example:

- A Winter Meeting of the Optics and Atomic and Molecular Physics Sections which took place at Paris in January covering non-linear optics, holography, interferometry, thin films, diffraction, optical memory, atomic level shifts in the laser-matter interaction, etc.;

- An International Conference which was held at Clermont-Ferrand in May on the study of charged particle tracks in insulators and their applications;

- A Conference on liquid crystals which was held at Montpellier in June covering the structure of nematics, structure of cholesterics, motions (hydrodynamics, laser inelastic scattering, nuclear relaxation), lipids, macromolecules;

- A National Conference on plasma physics organized at Orsay in June.

Another important event is the Exhibition held in Paris which has grown in size, in interest and in influence over the years. Universities and Government Laboratories present some of their latest research and many scientific instrument manufacturers and industrialists exhibit their latest products. Such is the demand to exhibit at these annual events that the Exhibition now has stands covering al-

The delegation of the French Physical Society photographed at the EPS Council meeting in Florence in April of this year. Left to right are: A. Kastler (delegate from Individual Ordinary Members), F. Netter (General Secretary), H. Curien, A. Berthelot (President) and M. Soutif.

together an area of around 6000 square metres.

A Publication Committee concerns itself with all matters of physics literature. Its main activity is to oversee the production of the 'Journal de Physique' which is distributed to all Members of the Society. Special issues are produced covering the colloquia organized by the Society and there is an annex on applied physics - 'Revue de Physique Appliquée'.

The Education Committee, which was set up in 1964, concerns itself with the extremely important questions involved in the teaching of physics. It includes experts both from the teaching profession and from the world of physics outside education and has carried out some vital work in the reform of science courses. Under the heading of education, the Society also organizes meetings with experts from other disciplines (particularly mathematics), holds conferences specifically for physics teachers, and organizes for young students a presentation of recent research progress. These lectures are given by leading physicists (in recent years the speakers have included H. Curien, A. Guinier and A. Kastler).

The Society awards several prizes each year in recognition of major contributions to physics:

The Robin prize is awarded for a distinguished life's work in physics; the Ancel prize for research in solid-state physics; the Cotton prize for work in atomic and molecular physics; the Langevin prize for theoretical studies; the Joliot-Curie prize for research in nuclear and high energy physics; and the Esclangon prize for work in applied physics.

There is also (of particular importance) the Holweck prize which is awarded in alternate years by the Institute of Physics and the Physical Society, UK, to a French physicist, and by the French Physical Society to a British physicist. This prize is awarded in memory of the famous physicist F. Holweck who was killed in Paris during the Second World War. 